\title{
Clinical Notes of a Series of Twenty-two Cases of Obstructed Labours, including Eight Cases of Induction of Labour, Four Cases of Symphysio- tomy, and Ten Cases of Cæsarean Section.*
}

\author{
By Robert Jardine, M.D., F.R.S.E., Professor of Midwifery in St. \\ Mungo's College; Physician to the Glasgow Maternity Hospital; \\ Examiner in Midwifery to the Scotch Conjoint Board, etc.
}

DURING the past year my colleagues and I have treated 703 cases in the Glasgow Maternity Hospital, and in this number we have had to deal with 98 cases of contracted pelvis. This is certainly an extraordinary proportion, viz., about 1 in 7 , and it does not by any means include all, but only those in which there was difficulty in delivery. The slighter forms, where delivery was effected by nature, are not counted. In the following paper I purpose giving notes of the cases of induction of labour, symphysiotomy, and Cæsarean section, which were done during the six months in which $I$ was in charge of the hospital. With one exception they were all cases of rickety pelves. The results as regards both mothers and children can be contrasted, and an idea can be formed of the relative value of the operations.

\section{Cases of Induction of Labour.}

CASe I. Mrs G., æt. 31, II-para, was examined under chloroform on January 27 th. The conjugata vera was estimated to be $3 \frac{1}{2}$ in. The pelvis was generally contracted as well as flattened. The child's head could be easily pushed into the brim. As the patient was only 7 months pregnant, and the head could easily be pushed into the brim, it was decided to allow her to go on for another fortnight. Her first labour had been terminated by craniotomy. The patient, unfortunately, did not return at the appointed time, and when labour was induced, one week later than the time set, the head could not be pushed through the brim. Krause's method was adopted and two sets of bougies were used, but the labour was very slow in coming on, taking fully 4 days. As the patient was showing some evidence of exhaustion, manual dilation was resorted to when the os was nearly fully dilated, and forceps were applied, but the head could not be got through in the Walcher position. Craniotomy was done. The child

\footnotetext{
* Read at a Meeting of the Edinburgh Obstetrical Society, April 13th, 1904.
} 
weighed 5lbs., minus the brains. If this patient had returned at the time stated possibly the head would have come through, but I think I made a mistake in allowing her even a fortnight. It would have been safer to have had her back for examination in a week, but the head came down so easily that I concluded she could safely stand a fortnight more. The patient made a good recovery.

CASE II. Mrs. McD., X-para, æt. 33. The obstetric history of this woman is a somewhat remarkable one. Her first three labours were at home, and all the others in the hospital. The first child was born dead, spontaneously, at the 7 th month; the second one spontaneously at full time, dead; the third spontaneously at the 8 th month, also dead, the next five labours were by induction at the eighth month; the fourth and fifth children lived, the sixth died five hours after birth, the seventh was born dead, and the eighth lived five days; the ninth and tenth labours came on spontaneously at the eighth month, and the children both lived. The present labour was the tenth. The conjugata vera was $3 \frac{1}{2}$ in.

The patient was admitted for induction of labour, but on the day following it came on spontaneously. Two hours after its commencement the membranes ruptured and the cord prolapsed. The os was fully dilated and the pains strong. During the pains the pulsations of the cord could not be detected, but in the intervals they were quite perceptible, but very slow, only 60. An unsuccessful attempt was made to replace the cord with the patient in the knee elbow position. She was then put deeply under chloroform, and when the uterus relaxed the head was pulled back from the brim by external manipulation through the abdominal wall, and the cord, which was now pulsating strongly, was replaced and the head was pushed well down into the brim. The uterus was then massaged and a frm binder applied. The labour was completed in an hour's time without assistance. The child, a male, was alive, and weighed $635 \mathrm{lbs}$. The patient made a good recovery.

Strictly speaking, one can hardly call this an induction case, but the woman's obstetric history is so interesting that it is worthy of record. Ten labours up to the age of 33 is a pretty fair record of itself, but as she has only had one full-time one she has gained at least one month in nine of her pregnancies, which gives her an advantage over ordinary women. I have in several other cases found labour come on spontaneously shortly after the patients have becn admitted for induction. The excitement probably has something to do with it.

Case III. Mrs. L., II-para, æt. 20. Conjugata vera 3 Tin. This patient's first labour had been a forceps one, with a dead child. She was. eight months pregnant. Two sets of bougies were used, and after two days, as the patient was beginning to show indications of exhaustion, 
chloroform was administered the dilation completed manually, and the delivery effected by forceps. The child, a female, was alive and survived. The mother made a normal recovery.

CASE Iv. Mrs. G., III-para, æt. 25, conjugata vera $3 \frac{1}{2}$ in. The two previous labours had been very difficult forceps ones at full time, with live children. The deliveries had been so difficult that the patient was advised to have induction about the eighth month. Bougies were inserted, and on the following day a Barnes's bag, which rapidly induced contractions. The child, a male, alive and weighing $5 \frac{1}{2}$ lbs., was born by natural efforts. It seemed all right, but on the fifth day it died somewhat suddenly. The mother made a normal recovery.

CASr v. S. G., single, III-para, æt. 22, conjugata vera 3 thin. The first child had been born dead without assistance. The second had been delivered by craniotomy. Two sets of bougies were used. The child, a female, weighing 5lbs., was born alive and survived.

CASE vi. Mrs. T.,, III-para, conjugata vera $3 \frac{1}{2} \mathrm{in}$. This patient had had induction successfully performed twice before. Bougies were inserted for 24 hours, and then taken out and eight hours later labour came on and child was born by natural efforts. It weighed $4 \frac{3}{4}$ lbs., and was dead. This patient had been under chloroform for the insertion of the bougies. Before the chloroform was given the child was alive, but no examination for the fotal heart was afterwards made. The patient, however, was positive that she felt no movements after she became conscious. I remember one other case where the fœtal heart was quite strong before chloroform was given, and yet the child was born dead very shortly afterwards. This was a very easy forceps delivery, and there was certainly nothing in the delivery to have caused the death unless it had been the chloroform. I am inclined to think that chloroform may occasionally cause the death of the foetus in utero, but as yet I have no evidence to offer on this point.

CASE vir. Mrs. P., III-para, æet. 30, contracted pelvis, c. v. by postmortem measurement $3 \frac{5}{8}$ inches. On November 1st bougies were introduced. Some hours later the patient's temperature rose to $99.8^{\circ} \mathrm{F}$, and then fell to subnormal. On the 2 nd it rapidly rose to $103^{\circ} \mathrm{F}$, and the bougies were taken out. The labour soon after ended naturally, but the child was dead. An intra-uterine douche was given and the temperature quickly fell to normal, but it rose again to $102.8^{\circ} \mathrm{F}$. in the evening. After that it kept up about $102^{\circ} \mathrm{F}$., and finally rose to $105^{\circ} \mathrm{F}$. on the seventh day of the puerperium, when the patient died. Throughout the lochia remained perfectly sweet, and there was nothing to indicate any septic infection.

The post-montem examination showed that the heart was fatty and enlarged, the right ventricle dilated and thin. The pulmonary orifice was 
dilated, but all the others were normal. There were ante-mortem clots in all the cavities.

The lungs were emphysematous, but not consolidated in any way. There was no evidence of peritonitis. The lower 5 inches of the ileum appeared to be slightly congested, but on opening it there were no signs of any lesions of the mucous membrane. The uterus was enlarged, but its walls were quite healthy. The interior contained some dark red pultaceous material, but this was not septic. The spleen was slightly enlarged, but of normal consistence.

Whatever caused the death, it certainly was not septicæmia. The fatty dilated heart probably gave out, but what caused her temperature? I must confess I do not know, neither do. I know what caused her child's death. It was not a case of enteric as the Widal reaction was negative and there were no intestinal lesions.

CASE III. Mrs. T., æt. 25, III-para, conjugata vera $3 \frac{1}{4}$ in. The first child was born at full time by forceps, and lived a fortnight, the second one was born by induction and lived eight months, but then died of diphtheria. On the evening of admission she was prepared for induction, and $I$ intended demonstrating to the students the method of inserting bougies, but during the night labour pains commenced, and in the morning I found the os would admit two fingers, but the pains had ceased, so I introduced the largest Barnes's bag. It was expelled an hour later, and the labour was allowed to go on until the following day, when it was ended by forceps. The child was alive, and weighed $6 \frac{1}{2} \mathrm{lbs}$. It did well, and the mother made a normal recovery.

In this case I had seen the patient ten days previous to her admission, and after a careful estimate of the size of the head relative to the pelvis had concluded to allow her to go ten days longer. At the first examination the head had not presented, but by external version $I$ had no difficutly in manipulating it round and easily pushing it into the brim.

Remarks. These constitute all the cases in which induction was done in the interests of the child, but there were several others where it was done in the interests of the mother, as for albuminuria and exhaustion from severe vomiting. I have omitted these, as this paper is only dealing with cases of obstructed labour.

In his "Obstetrics," Whitridge Williams says: "At the present time, then, it seems to me that the only rational indication for the induction of premature labour, so far as concerns the existence of disproportion between the size of the head and the pelvis, is afforded by the rare cases in which the pelvis is normal, but the child abnormally large, owing either to excessive development or to an 
undue prolongation of pregnancy. If such a condition be diagnosed some weeks before labour, the operation is clearly indicated, particularly in multiparous women who have repeatedly given birth to very large dead children." Pinard considers the operation no longer justifiable, and advocates symphysiotomy at full time, and Bar, likewise, has abandoned it and recommends Cæsarean section at term, if spontaneous delivery does not occur. There can be little doubt that more children will be saved, but I do not believe that even in the hands of expert operators the maternal mortality will be as low as after induction of labour. I think most British obstetricians will agree with me that it is a perfectly justifiable operation in properly selected cases, especially in the hands of general practitioners who can hardly undertake such serious operations as symphysiotomies or Cæsarean sections. In hospitals it will probably be done less frequently in the future, but even there there is a place for it until, at all events, the mortality after the cutting operations has become much lower than at present.

As regards the cases suitable for induction they are practically the same as those for symphysiotomy. I have frequently induced labour with a conjugata vera of $2 \frac{3}{4} \mathrm{in}$., but I am bound to say the results to the children have been far from satisfactory. The great point to decide the matter is the size of the head relative to the pelvis, provided that the child has reached an age at which it. will have a good chance of surviving. At 28 weeks a child may live, and I have been able to bring up one at least a week younger than that, but the chances of its surviving are not very brilliant. In fact, to give the child a reasonable chance the 32 nd week should have been reached. The nearer full time the better.

If the head will not pass the brim at the 32nd week, I think one should decide upon an operation at full time, preferably Cæsarean section. On the other hand, if the head can easily be pushed into the pelvis, we should wait, seeing the patient week by week, until the time comes, when the head enters the brim with difficulty. Labour should then be induced without delay. The method of judging of the size of the head relative to the pelvis was so recently described to you by Dr. Munro Kerr that I shall not occupy time in going over it. To show the importance of observing the patient I would refer you to the Scottish Medical and Surgical Journal of October, 1903, p.p. 291, where I describe a case with a $2 \frac{3}{4}$ in. pelvis, which I allowed to go to full time with the result of a live child born by natural efforts.

There are certain cases where I am quite sure the vitality of the 
prematurely born children is too low for them to survive, although they are well developed and are born without difficulty. I remember one case where $I$ induced labour three times running, and got live and well-developed children, and yet they died in a few days. There was no syphilis in the case. On the fourth occasion I refused to induce labour, and insisted on a Cæsarean section at term, and got a fine healthy child.

\section{Cases of Symphystotomy.}

CASR I. Mrs. D., III-para æt. 19, was admitted in labour at full time. Her two previous deliveries had been by craniotomy, and on each occasion the child's head had been firmly ossified. The pelvis was a flat, rickety one, with a c. v. of 3 in. The foetal head overlapped the symphysis considerably.

The symphysis was opened in the usual way, cutting directly down upon it. Forceps was applied, and the head extracted without difficulty, with the patient in the Walcher position. The ends of the bones separated about two inches. The child, a male, was alive, and weighed 7libs. The symphysis was easily brought together and several strong catgut sutures were put through the fibrous tissue and the superficial wound was closed with silk worm gut.

The patient made a very good recovery for a week, when she developed bronchitis, which gave some trouble for a few days. A fortnight after the operation she developed incontinence of urine, which was treated by the insertion of a winged catheter for three days. After that there was no further trouble. She was dismissed quite well on the 37 th day, able to walk without any inconvenience.

CASE Ir. Mrs. H., V-para, æt. 29, was admitted from the outdoor department after failure to deliver with forceps. All her former children had been delivered by forceps with difficulty, one of them dead. The conjugata vera was estimated at $3 \frac{3}{4} \mathrm{in}$. The head was large and would not engage.

Symphysiotomy was performed by my assistant, Dr. Gibson. Considerable traction was required to deliver the child with forceps. It was a female, alive, and weighed $11 \frac{1}{2} \mathrm{lbs}$. The head was very large and square, the bi-temporal diameter being $3 \frac{5}{8}$ in., the bi-parietal $3 \frac{3}{4}$ in., the sub-occipito-bregmatic 4 in., and the occipito-frontal $4 \frac{7}{8}$ in.

The patient made an extremely good recovery, and was dismissed quite well on the 31 st day

CASR IIr. Mrs. B., I-para, æt. 24, was admitted after having been in Iabour for 30 hours. A midwife had been in attendance all night, and the people stated that she had been most attentive and had examined the 
patient at every pain. She had ruptured the membranes five hours before the patient was admitted. The os was found to be dilated, and the head presenting but not engaging. It overlapped the symphysis considerably. The conjugata vera measured $3 i n$, the interspinous diameter $8 \frac{3}{4}$ in., and the intercristal $8 \frac{1}{2} \mathrm{in}$., so we had to deal with a generally contracted as well as a flattened pelvis. The case was not a good one for symphysiotomy, but, on the other hand, it was an extremely bad one for Cæsarean section unless one did a hysterectomy. I therefore decided to do symphysiotomy. After cleansing the vagina as thoroughly as possible, I operated in the usual way, but while dividing the symphysis from above downwards I came upon solid bone about half-way down the joint. I was using a heavy Galbiati's knife, and tried to cut through the obstruction, and in doing so turned the edge a little towards the left side to see if it was merely a bend in the joint, as I had once before found in a case. The bone suddenly yielded, and the joint gaped. I found that the bone had given way into the obturator foramen, and at the same time the left ramus had fractured just about the junction of the ischium and pubis. The child was delivered with forceps. It was a female, alive, and woighed $7 \frac{1}{2} \mathrm{lbs}$.

During delivery the fractured end of the ramus caused a laceration into the vagina. The symphysis was brought together in the usual way, and also the fracture. To ensure drainage $I$ plugged the vaginal tear with iodoform gauze. Contrary to my expectations the patient made a fairly good recovery. There was moderate pyrexia for a few days. The sinus was washed out carefully and the packing renewed daily for about a week. The patient was dismissed well on the 42 nd day. The fracture had united, and there was a fair amount of callus, but nothing excessive. If this woman should come under my care again at full time, I think, I shall do a Cæsarean section.

CASE Iv. Mrs. M., III-para, æet. 30. This patient's previous labours had resulted in dead children, the second one being at the 7 th month by induction, I think. She was sent in by my colleague, Dr. Munro Kerr. The conjugata vera was $3 \frac{1}{2}$ in. The os was fully dilated.

I operated at once. The child, a female, weighing $8 \frac{1}{2}$ lbs., was delivered alive with forceps, the patient being in the Walcher position. There was a good deal of tearing of the soft parts, and the bleeding was very free. I found the distal end of the urethra had torn away from the vagina. I was extremely lucky in getting a catheter into it at once, as it had retracted a considerable distance into the wound and could not be seen. I pulled it down and stitched it in position again. The symphysis was then closed and the wound firmly plugged with iodoform gauze to check the bleeding. The catheter was tied in and left for three days. After a couple of days the gauze packing was replaced by a drainage tube. There 


\section{Jardine: Twenty-two Obstructed Labours}

was some febrile disturbance for a few days, but the progress was satisfactory.

Remarks. I doubt very much if the operation of symphysiotomy will ever become a favourite one in this country. Personally I am not very much taken with it. I have now performed it six times successfully so far as the mothers were concerned, and with the loss of one child. In two of the cases the hæmorrhage was very severe, and in nearly all there was considerable laceration of the soft parts. It is impossible to prevent this laceration if you require much separation of the joint to allow of delivery, as the soft parts in the front are quite unsupported. In primiparæ this is especially the case, and they are much less suitable for the operation than multiparæ, who have relaxed vaginæ. Another drawback to the operation is the subsequent nursing of the case. To get union of the joint the patient must be kept lying very still, and this is no easy matter, when her wants have to be attended to. The case is worse than a fractured pelvis, because the lochial discharge as well as the ordinary wants of nature have to be attended to. I know the nursing staff would sooner attend to three cases of Cæsarean section than one of symphysiotomy. Again, the length of convalescence required is at least two weeks greater than after a Cæsarean section.

There is no doubt that there is a slight permanent increase in the size of the pelvis, and subsequent deliveries may be accomplished by forceps. In my first case this was so, but $I$ have not had an opportunity of testing this in any of the others. ${ }^{1}$

As to the length of the conjugate to which the operation is applicable, it works out very much the same as for induction of labour, and, roughly speaking, one may say that $3 \mathrm{in}$. is about the lowest limit, but the relative size of the head must always be borne in mind.

\section{Cases of Cessarean Section.}

In the following 10 cases Crsarean section was performed. In two of the cases, which I shall give first, supra-vaginal amputation of the uterus was also done, and in both of these the children were dead before operating. The first case was done for extensive cancer of the cervix and the other 9 for markedly contracted pelves.

CASE r. Mrs. C., VI-para, æt. 35, conjugata vera normal. Until within 8 weeks of the time of admission the patient had not had any

${ }^{2}$ Since this was written I have delivered by forceps a woman who has had symphysiotomy performed in her last two confinements. The child was saved, although the cord was prolapsed before the patient was admitted. 
symptoms of special significance. From then she had been troubled with pretty severe pelvic pain of a radiating character, and a reddish vaginal discharge. During the last week she had had several severe attacks of bleeding, and the doctor who had sent her in said that she had lost about 30 ounces of blood that evening. She was near full time.

On examining her I found she was a very stout woman, somewhat anæmic from the loss of blood. There was no fœetal heart to be heard. Fotal movements had ceased for 3 days. A vaginal examination revealed that there was a large cancerous mass involving both lips of the cervix and extending out on to the vaginal wall, especially on the left side. The greater mass was in the anterior lip. The cervical canal admitted the finger, and the cancer was found to implicate the entire cervix, which was from $2 \frac{1}{2}$ to 3 inches in length. The head presented. There was some slight bleeding during examination.

It was quite evident that it was impossible to remove the entire cancerous mass, as it extended too far out on the vaginal wall, but after considering the case fully, I decided to operate at once and remove the uterus supra-vaginally, and thus control the hæmorrhage. It might have been possible to have scraped away the cancer to a sufficient extent to have allowed of delivery by craniotomy, but in doing so I was afraid the bleeding might cause the patient's death. As the child was dead there was, of course, no necessity of considering it.

On incising the thick abdominal wall there was no bleeding. I was so struck with this that I thought the patient must have died, but she was breathing well. There was the same bloodlessness in the uterine incision. I left the placenta in the uterus, cutting the cord off short, and as there was no bleeding did not apply clamps or an elastic ligature round the uterus. The cancer had spread upwards into the lower uterine segment, so the amputation incision passed through cancerous tissue. The stump was stitched and the peritoneum closed orer it. The pelvic glands, especially on the left side, were deeply involved. The loss of blood was extremely small. A quart of normal saline solution was left in the peritoneal cavity. The child weighed $9 \frac{1}{2} \mathrm{lbs}$.

The after progress of the patient was satisfactory, but during the third and fourth weeks there was feverishness partly from absorption from the cancerous mass, but also from the sloughing of a burn on the thigh caused by a hot water bottle after the operation. The patient suffered no pains in the pelvis, and the cancerous mass shrunk to a certain extent. She went home on the 28 th day, and was still alive two months later, but $I$ am afraid she could not survive much longer.

CASE II. B. S., an unmarried rickety dwarf, æet. 23, c. v. $1 \frac{1}{2}$ in., was brought into the hospital from the country. She had been in labour for a 


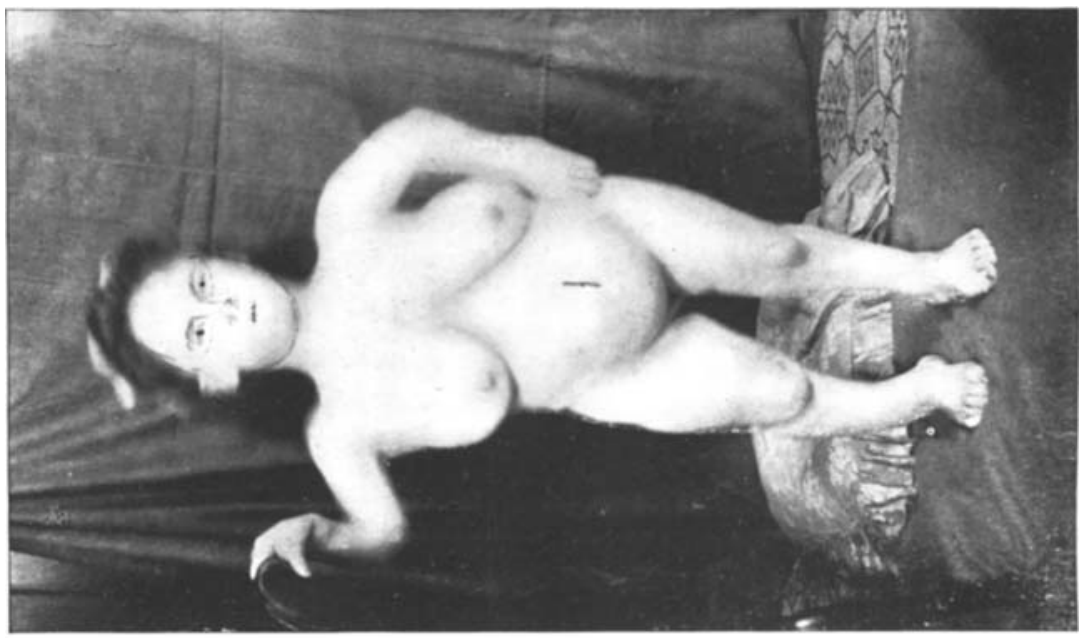

占

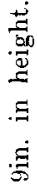

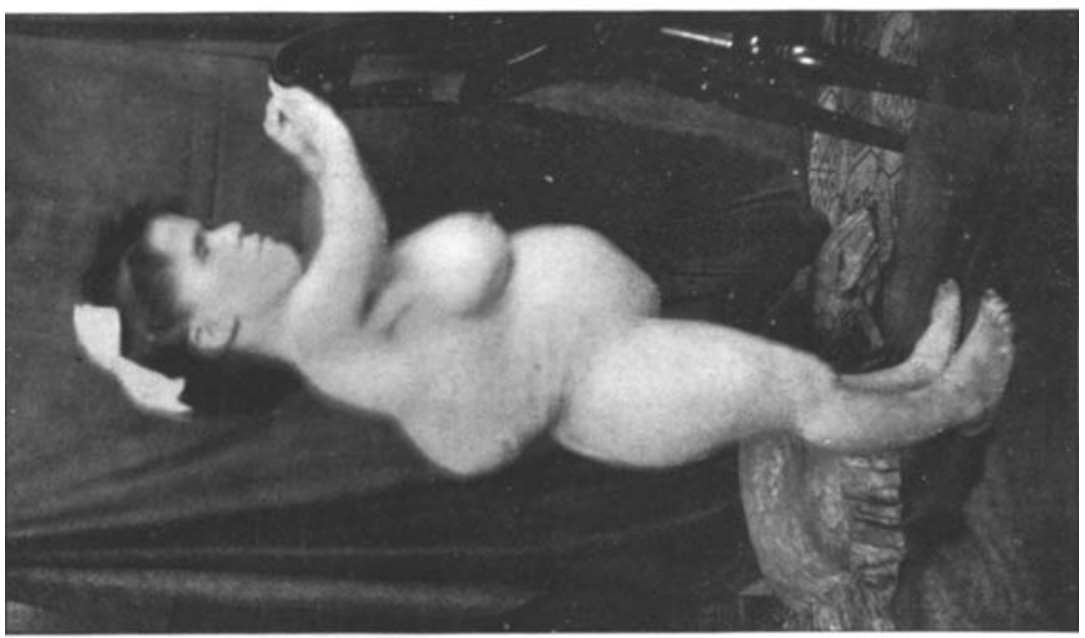

t

ส

8

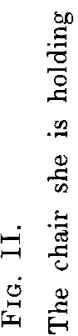

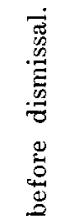

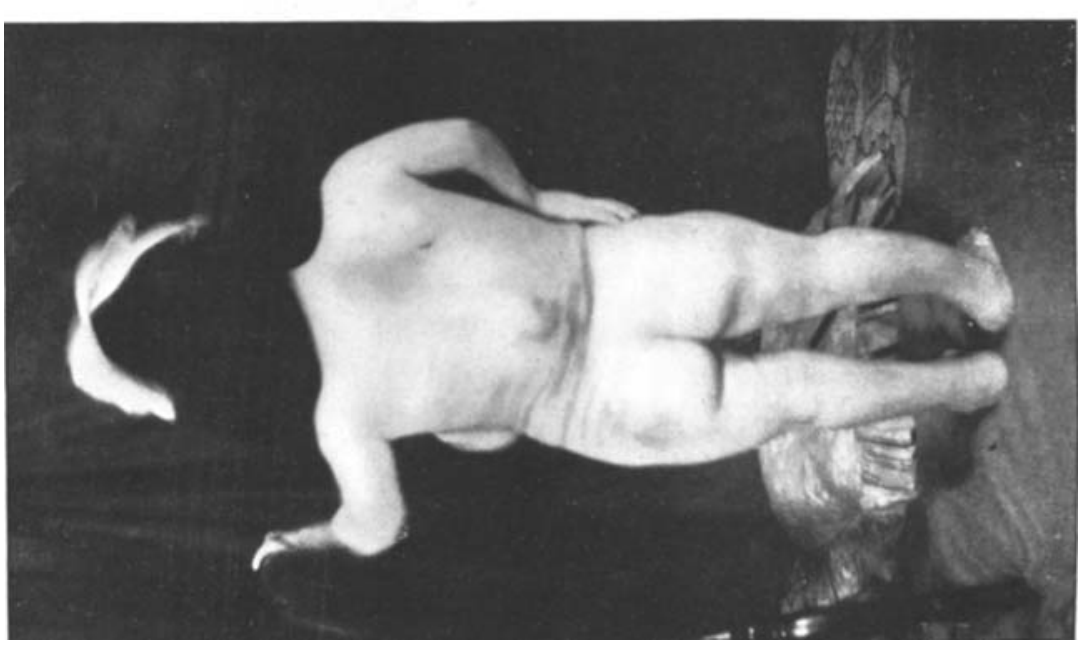

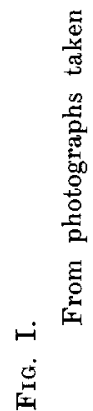


considerable time, and the cord was prolapsed and quite pulseless. The patient was $3 \mathrm{ft}$. $7 \frac{1}{2} \mathrm{in}$. in height and very markedly deformed, as will be seen from her photograph (see Figs 1, 2, and 3). The conjugata vera was a little over an inch and a half. Even with a dead child, craniotomy was out of the question, so there was nothing for it but an abdominal section, although the patient was anything but a good subject. As the chances were that the uterus was septic, I determined to amputate it. I operated as soon as she could be prepared. There was very little blood lost during the extraction of the child, and none afterwards, as $I$ at once clamped the uterus low down. The ovaries were both healthy, so I left them. The patient stood the operation well. She liad a somewhat febrile recovery, and developed a couple of stitch abscesses, and later on a large abscess under the outer edge of her right breast, which burrowed under the scapula and pointed in the back.

CAsE III. Mrs. P., æt. 27, II-para, c. v. 21in. Just 10 months previously this patient had been delivered in the hospital of a $4 \frac{1}{2} \mathrm{lb}$. child by craniotomy after a midwife and a doctor had failed to deliver her at her home. She was extremely rickety, with a true conjugate of barely $2 \frac{1}{2}$ in.

When she was about three months pregnant this second time I saw her and advised her to have Cæsarean section done. She was to have come to the hospital on June 1st, but did not turn up; however, on the evening of that day she sent me word that she was having pains. According to her dates the labour was not quite due. I saw her at her home, and found the os was beginning to dilate, so at once sent her into hospital to bo prepared for operation. I noticed that she was very stout, but, as she was fully dressed, I did not palpate her abdomen, so did not diagnose twins.

Two hours after admission I operated. Just as I was about to begin the abdominal incision she stopped breathing. The tongue was pulled forward and artificial respiration commenced, but there was no effort at gasping, so I quickly opened the abdomen and cut into the uterus. The placenta was situated anteriorly, and the first sweep of the knife was followed by a large spurt of blood, and the patient at once gave a gasp. The uterine incision was quickly enlarged and a child removed, and I then found there was a second one. Both children, males, required to be resuscitated. They each weighed $4 \frac{1}{2} \mathrm{lbs}$, and were so much alike that afterwards nobody could tell which had been born first. If they had been children of aristocratic parents, and had survived, I am afraid there would have been difficulties in settling the point. As it was, the registrar was very indignant that we could not tell which was the elder of the two. I advised the nurse to tell him that according to Shakespeare they were 
never born at all, but were, like Macduff, from the "mother's womb untimely ripped." I do not know how he settled the point.

The patient breathed quite well after the uterus was emptied, and gave no further trouble. The operation was finished in the usual way, and as the woman wished it I tied and cut her tubes.

The children seemed to thrive for two weeks, and then they suddenly began to pine, and one died on the 18 th and the other on the 21 st day.

I had once before had the unpleasant experience of failure of breathing just as I was beginning the uterine incision, and in Case v. the same thing happened. In all of these cases the abdomen was very tense. In the first case artificial respiration was kept up for some minutes, and I thought the patient was dead, so quickly opened the uterus to save the child. The mother then breathed at once. In the other cases I did not wait any time, but went on with the operation, while the assistants were doing the artificial respiration. The free flow of blood helps the circulation by relieving the engorged heart, and the relief of pressure upon the diaphram allows of free play to the lungs. In cases of great distension $I$ think it would be advisable to rupture the membranes immediately before beginning the operation.

The patient made an uninterrupted recovery.

CASE IV. Mrs. H., æet. 27, I-para. This patient was admitted after having been in labour for 12 hours. The conjugata vera moasured $2 \frac{1}{4}$ in. She was at once prepared for section. The membranes ruptured before the operation. There was nothing to be remarked about the operation except that the uterus remained very flabby and did not retract well until it was replaced in the abdomen after it was sutured. The Fallopian tubes were not tied. The child, a female, was alive, and weighed 51 lbs.

The patient made an excellent recovery except that there was a stitch abscess, which, however, healed quickly.

Case v. Mrs. O., II-para, æt. 25. Conjugata vera $2 \frac{1}{4}$ in. This patient's first labour had ended in a craniotomy. She was very rachitic, being only $4 \mathrm{ft}$. 2in. in height. Her intercristal and interspinous diameters were the same, $9 \frac{3}{4}$ in., and the diagonal conjugate $3 \mathrm{in}$. She had suffered from chronic bronchitis for many years, and was in the hospital under treatment for this for 11 days before the operation was done. I was anxious to operate upon her during daylight, as I have found that in operating at night with the gas burning right over the table there is a good deal of decomposition of the chloroform, which causes bronchial irritation. On examining her on a Friday I found the os was patent, although there had been no pains, so I had her prepared for operation on the Saturday morning. During the night the 
pains came on. On the Saturday morning there was, unfortunately, a very dense fog, but as labour had commenced I was forced to proceed with the operation under the worst possible conditions for the patient. She took the chloroform badly, and just as I began the abdominal incision she stopped breathing and seemed to be dead. The tongue was pulled forward and artificial respiration begun while I went on with the operation. As soon as the uterus was opened breathing commenced, and we had no further trouble. Her tubes were tied and cut. The bronchitis was bad for several days, but otherwise the recovery was uneventful. Her baby, a girl, weighed $7 \frac{1}{4} 1 \mathrm{lbs}$, and she was able to nurse it.

Case vi. Mrs. C., II-para, æt. 22, conjugata vera $2 \frac{3}{4}$ in. The first delivery had been by craniatomy. The pelvis was generally contracted as well as flattened. She was admitted in labour and was operated on at once. The membranes were extremely adherent, and to get them away I inverted the uterus through the incision. I did not tie her tubes. The child, a boy, weighed 73 Ibs., and she was able to nurse it. Her recovery was uneventful.

Cases ii., v., and vi. were all operated on within 14 hours.

CASE vir. Mrs. H. V-para, æet. 35. Conjugata vera 23in. This patient's first child had been born at full time, dead, either by forceps or craniotomy; her second, at full time, dead, a breech, craniotomy on aftercoming head; her third at the 7th month, dead, by forceps; and her fourth at full time by craniotomy. With such an obstetric history it was time for a Cæsarean section. Labour commenced on the day following admission. The operation was done as soon as possible after the pains commenced, but the membranes ruptured about an hour before I began. The only point to be noted about the operation was that the membranes were extremely adherent. To get them cleared off I inverted the uterus through the wound. The upper half of the abdominal incision was protected by a large gauze swab between it and the uterus. The report says the tubes were not tied, but I have an impression they were. The child, a boy, weighing $93 \frac{3}{4} \mathrm{lbs}$, was alive. Three hours after his birth pus was observed to be streaming from one of his eyes, although a 2 per cent. silver nitrate solution had been instilled. It was a very typical case of ophthalmia neonatorum, and the infection must have occurred in utero. When I discovered this I had grave doubts of the mother's recovery, and was not astonished to find her temperature rise to $101.2{ }^{\circ} \mathrm{F}$. It remained about that height for five days, and then gradually came down to normal. There was a great deal of abdominal distension. On the sixth day I washed out the uterus and dressed the abdominal wound. The wound seemed to be healing nicely, and there was no redness with any of the stitches. Two days later some discharge was found at the edge of the 
dressing, and on removing it the lower half of the wound was found to be sloughing very badly. The stitches were all removed and a wet dressing applied. The patient's temperature was now normal. On examining the parts carefully next day I found the upper half of the wound healed, but the lower half gaping fully an inch wide and sloughing badly. Towards the left a sinus ran downwards and outwards for fully three inches. There was also some undermining at the lower edge of the wound. The floor of the cavity was formed by the anterior uterine wall, and the catgut sutures were still present. The uterine incision was firmly healed. The portion of the abdominal incision which had sloughed exactly corresponded with the part which the inverted uterus had come in contact with. When the slough had separated I dressed the part with strips of iodoform gauze plugging steeped in Hey's wash. The parts soon took on a. healthy action and gradually closed, but it took two months before this was completed. The patient was very well when she left the hospital, and her temperature was never above normal after the stitches had been taken out. The ophthalmia subsided after a few days' treatment, and the baby throve well.

The whole of the anterior wall of the uterus was firmly adherent to the abdominal wall. If she should require another section it can easily be done extra-peritoneally.

CAse vil. Mrs. G., I-para, æt. 25, conjugata vera $2 \frac{1}{2}$ in. There was nothing to note about this operation. The tubes were not tied. The baby, a girl, was alive, and weighed $5 \frac{3}{4} l b s$. The recovery was uneventful, the temperature remaining normal throughout. The child throve splendidly.

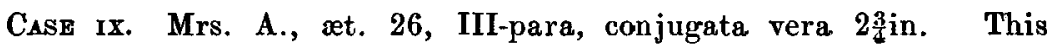
patient's two previous children had been delivered dead by craniotomy, I think. Both she and her husband were anxious that I should sterilise her, if the baby was alive and healthy. The child, a boy, weighed 8lbs., and to all appearances was a splendid specimen. Several of the men present at the operation remarked this. I, therefore, tied and cut the tubes. The patient made a perfectly normal recovery. On the second day the baby became intensely jaundiced, and died on the following day. A post-mortem examination did not reveal anything except that all the organs were bile-stained and the liver was enlarged.

CASE x. Mrs. M., æt. 23, II-para, conjugata vera $2 \frac{3}{4}$ in. This patient's first child had been delivered by craniotomy. She was sent into the hospital from some distance in the country in labour. The os was nearly fully dilated, but the pains were not very strong. A hypodermic injection of $1 \mathrm{gr}$. of morphia was given to lessen the pains while the abdomen was being prepared for section. The membranes had ruptured before the operation was commenced. There was nothing to note in the 
operation except that the uterus remained very flabby until it was returned into the abdomen. The child, a female, weighed $6 \frac{1}{2} l b s$., and throve well. The mother's tubes were not tied. The recovery was uneventful.

Remarks. In performing the operation the method which I have adopted is to make an abdominal incision of about $5 \mathrm{in}$. in length high up, so that about two thirds of it lies above the umbilicus, and then to incise the uterus longitudinally in the middle of the anterior wall so that the top of the incision will be at the fundus. I generally use Cameron's pessary to prevent bleeding from the uterus while incising it. The child is delivered by grasping one leg. The old notion of the incision grasping the aftercoming head is fanciful. I have only once experienced difficulty in delivering the child, and that was in a case where the membranes had been ruptured, and the retraction ring had grasped the child round the neck. It required considerable force to dislodge the head. In nearly every case the child requires to be resuscitated. This may be partly due to the chloroform, but $I$ think the sudden reduction of temperature in the uterus when the abdomen is opened may so stimulate the child as to cause it to make inspiratory efforts and thus draw liquor amnii into its lungs. I have more than once emptied several ounces of liquor amnii from the lungs by inversion of the child.

As regards the position of the placenta it has been on the anterior wall in nearly nine-tenths of my cases. In the 10 just recorded $I$ came either directly on to it or on to its edge in every one of them except in case 1 where it was on the posterior wall. When it is in the anterior wall the hæmorrhage will be a little greater, but it can be easily controlled. As a rule, the hand is not passed through the placenta, but round its edge by stripping it off.

In all of the cases recorded I used catgut sutures for the uterus, and silk to tie the tubes. I have tried silk and also celluloid thread for the uterine sutures, but in many of the cases the sutures worked out long afterwards and gave great trouble to the patients. When catgut is used it should be tied very firmly, as there is risk of it becoming untied. I have known this happen and cause the patient's death from hæmorrhage. The sutures do not include the mucous membrane.

The uterine incision I have always practised is a high longitudinal one. The fundal incision $I$ have never taken to, and after a case I saw recently in the hands of my colleague, Dr. Munro Kerr, I have less love for it. The patient had not been sterilised, and just at the onset of labour in the next pregnancy the old wound 
gave way and the intact ovum was extruded through the fundus into the abdominal cavity. The uterus had retracted well and there was little bleeding. The patient recovered after hysterectomy, but the child was, of course, lost.

The operation is usually done after labour has commenced, but one need not wait for the actual labour pains. I have several times operated before active uterine contractions had commenced. In such cases, if the uterus is to be left, the os should, of course, be sufficiently dilated to allow of free drainage. The woman is thus saved the exhaustion of labour, and one can select a suitable time for the operation during the day instead of being hurriedly called perhaps in the dead of the night.

In suitable cases Cæsarean section is an operation which may be done with comparatively little risk if proper aseptic precautions are taken. If the cases can be admitted a few days before full time so as to have them properly prepared for operation one may confidently expect a good result, but, unfortunately, many of the patients are only admitted after labour has been going on for a considerable time. The risk in such cases is greatly increased, especially if the patient has been repeatedly examined in the usual haphazard way without proper aseptic precautions. I have never lost a case which I have had under observation for a few days prior to the operation, and I now make a rule not do a section if the patient has been repeatedly examined prior to admission, unless there is an absolute indication, as in case 2 , and then the uterus should be removed. I remember one case which was admitted after several examinations had been made by a midwife and two doctors. The child was alive, but I decided to do a craniotomy. By the second day the patient had developed violent sepsis, and $I$ am quite sure that if section had been done and the uterus left, the patient would have been dead within 48 hours. If there is any septic vaginal discharge the uterus should be removed.

The question of sterilising the patient is a very important one. In this series of cases $I$ tied and cut the tubes when specially requested, to prevent future pregnancies. If the husband and wife are both desirous of having this done, I think one is perfectly justified in doing the operation, and as these patients are usually very prolific it comes to be a serious business for a woman to require such a major operation, say, every 2 years or so. I have not yet had to repeat the operation, but in the event of having to do so, I think, I shall take steps to prevent any future pregnancies. Tieing and cutting the tubes $I$ have found quite effectual, and it should be 
so, if it is properly done. Some operators advocate the removal of the uterus in all eases in which it is advisable to sterilise the patient. Herman advocates this, and says, "except for child-bearing the uterus is useless; it is liable to disease, and it menstruates, which is a monthly illness." $\mathrm{He}$ also adrocates the removal of the ovaries because they "may become cystic." It is true that child-bearing is the chief function of the uterus, but I do not believe that this is its only function. To call a strictly physiological process like menstruation an illness seems to me to be as unscientific as to urge as a reason for removal of the uterus and ovaries that they may become diseased. To unsex a woman in the prime of life is an unjustifiable proceeding, unless the step is rendered necessary by disease. If the removal of the uterus will lessen the risk of the operation then it should certainly be removed, as was done in cases 1 and 2 , but in ordinary cases it should be left. If the ovaries are healthy one or both should be left. 